\title{
Value Stream Mapping for Evaluation of Load Scheduling Possibilities in a District Heating Plant
}

\author{
Raivo Melsas, Argo Rosin and Imre Drovtar
}

\begin{abstract}
Demand side response enables cost optimization for energy systems and industrial consumers. In many countries, it is not widely used because of implementation complexity. One of the solutions for applying demand side response is industrial process scheduling according to the energy market needs. From the energy system point of view, process scheduling implies load scheduling. The aim of this paper is to provide a solution for load scheduling by implementing value stream mapping, which is a straightforward enough for production management. Decision makers in the industry should have a clear understanding about positive effect from load scheduling and its effect to production outcome and process availability. Value stream mapping is a wellknown process optimization tool from lean production philosophy. The aim of value stream mapping is to shorten the lead time of industrial processes and to reduce the intermediate stock amounts. By complementing value stream map with process energy intensity and energy stored in intermediate stocks, we can promote load scheduling possibilities. Our methodology provides a tool that is understandable and traceable for industry-minded decision makers. Finally, we present a real life test example for the new methodology, which is based on the production process of a district heating plant.
\end{abstract}

Index Terms - demand response, energy storage, load management, load scheduling, value stream mapping

\section{INTRODUCTION}

$\mathrm{L}$ OAD scheduling (LS) as part of demand side response (DSR) must meet the needs of industry. One of the effects for the industry appears when load consumption is shifted from periods of high electricity price to those of low price. As a result, cost savings can be achieved by means of reduced consumer demand in high price periods. This requires better production planning, which is related to production management.

Previous DSR studies have resulted in the following: static Stackelberg game theory for voluntary load curtailment programs [1]; numerical calculation method for DSR when a battery energy storage system (BESS) is utilized [2]; solutions for DSR by means of automatic lighting [3]; DSR with microCHP systems [4]; an overview for DSR methods in high

This research was supported by the Estonian Centre of Excellence in Zero Energy and Resource Efficient Smart Buildings and Districts, ZEBE, grant 2014-2020.4.01.15-0016 funded by the European Regional Development Fund. consumption industries and examples of market tools that support DSR [5]. In [6] an automated complex system for LS in industry is described, which takes into account stock restrictions, maintenance schedules, and crew management. All the necessary inputs are analyzed with a fuzzy/expert-based system combined with an optimization module. As a result, the system is able to identify whether and how much the industrial plant can participate in a DSR event. In [7] and [8] DSR is addressed as a part of the following main load shaping strategies:

a) conservation - energy saving is achieved through static methods;

b) load growth - energy consumption is increased when an energy system has surplus energy production;

c) valley filling - load is increased through the off-peak periods or keeping stable consumption;

d) peak clipping - energy consumption is decreased in peak periods;

e) load shifting - peak consumption is shifted from peak periods to non-peak periods;

f) seasonal load reduction - annual energy peaks are reduced.

LS is used mainly in "load shifting" strategy e; however, in some cases, "valley filling" strategy can be utilized as well. To use the LS, an industry must have the following one or several DSR options [8]: cooling equipment with cooling storage, heating equipment with heat storage, dual fuel systems that can operate either on electricity or on an alternative fuel, discretionary loads and process equipment that can be shifted during a short period or material handling equipment with storage possibilities (silos, stock, etc.). This paper focuses on the last option by looking at process as a whole in order to find LS solutions. In addition, it provides a method applicable in industry for outlining the possibilities with LS as a part of DSR by using value stream mapping (VSM). VSM is applicable in

R. Melsas, A. Rosin and I. Drovtar are with the Department of Electrical Engineering, Tallinn University of Technology, Ehitajate tee 5, 19086 Tallinn, Estonia (e-mail: raivomelsas@gmail.com, argo.rosin@ttu.ee, imre.drovtar@gmail.com). 
various ways. Originating from Toyota Production Systems [9], it was further elaborated and adjusted to find solutions for different problems in the production process. For example, VSM is used to solve quality problems [10]. This paper elaborates on VSM. Our proposal is to use it for indicating a possibility to shift an electrical load from a high price period to a low price period and utilize an intermediate stock for energy storage [11], [12], [13]. This paper will provide a straightforward solution for the industry in order to apply LS effectively and which is easily applicable.

\section{II. ENERGY PRICE AS A DRIVER FOR LOAD SHIFTING}

LS can yield an economic effect under rational consideration. Cost reduction can be achieved by taking advantage of energy price fluctuations during a day. It is reasonable to have demand response implemented in countries where an electricity pool exists and hourly based spot prices are known for a short period ahead. As a result, industries can plan their production according to the spot price. Fig. 1 shows an average 24-hour electricity market spot price in Estonia in 2014 [14]. As can be seen, electricity spot price is typically higher from 07:00 A.M. to 8:00 P.M. In general, there is at least 10-euro price difference during a day and a night. Considering the price peak and dip approximately 20-euro difference per MWh exists during a day. On average, price difference during a day is 15-euro MWh.

However the consideration above includes only electricity price; in addition, there are some fluctuations in grid service price as well. From 12:00 A.M. to 8:00 A.M. (11:00 P.M. to 7:00 A.M. in winter time), the grid service price is lower. This period is not overlapping $100 \%$ with a low spot price period. We will call this period (12:00 A.M. to 8:00 A.M.) as the Low Price Period (LPP) and the other period during a day as the High Price Period (HPP). Grid tariffs depend on grid connection voltage level and connection capacity (amps). In the following, we will describe one example to examine the daily price difference for the industry in Estonia.

At substantial electricity consumption, an industry is usually connected into a middle voltage (MV) grid. In that case, Estonian grid service price is 14.5 euros per MWh from 8:00 A.M. to 24:00 A.M. and during LPP 8.3 euros per MWh [15]. For some customers, no time difference is applied; the price for grid services is constant in time- 12 euros per MWh. Fig. 1 shows both the grid price and the spot price fluctuations.

In 2014, an average electricity spot price for LPP was 29.5 euros per MWh and with grid price fluctuations it amounted to 37.8 euros per MWh, which we call as the Low Price Period Price (LPPP). In 2014, an average HPP spot price was 40.9 and together with grid tariff, the average number was 55.1 euros per MWh, which we call as the High Price Period Price (HPPP). For clarity, 55.1 is an average found on hourly bases, i.e. spot price + grid price.

Based on the data provided, we can calculate potential savings for industry under LS. Potential cost saving is $31 \%$, which is calculated by (1):
$C S=\frac{H P P P-L P P P}{H P P P}$

In general, it can be concluded that grid tariff fluctuation has an important role in LS in Estonia, as the average difference in the spot price between HPP and LPP was 11.4 euros per MWh and grid tariff will add extra for the difference between HPPP and LPPP, according to [15], tariff depends on the grid connection parameters.

The shape of the electricity spot price in Fig. 1 can be considered as a typical shape of the daily demand of electricity as well; a similar shape of demand can be found in various places, e.g., even in South Africa [16]. Thus, DSR has a positive impact to overall efficiency to energy systems, not only to an industry itself.

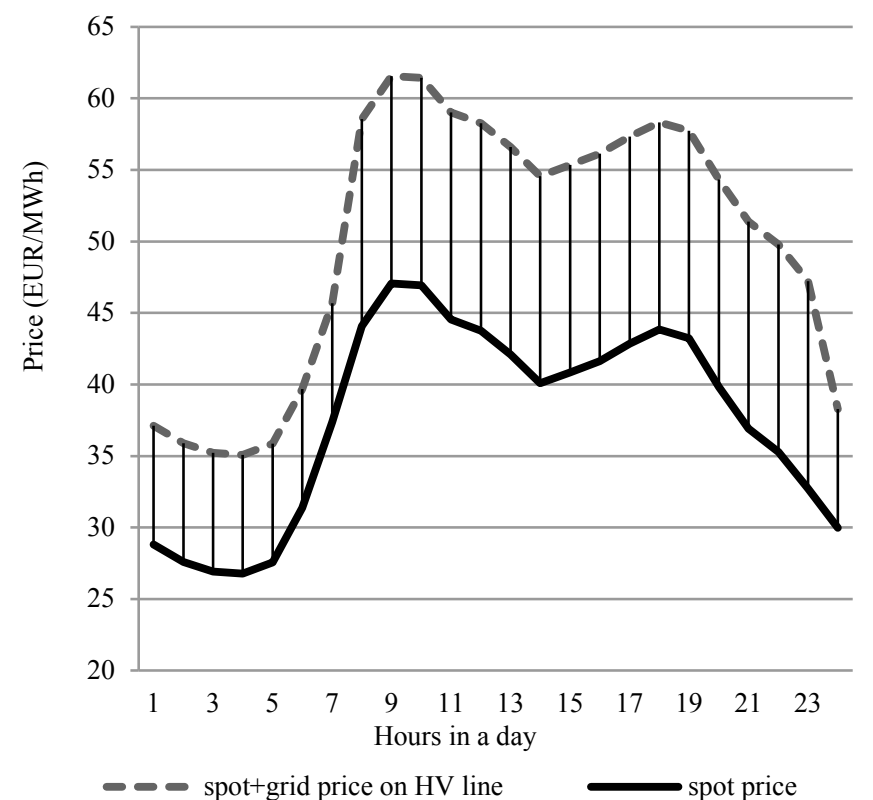

Fig. 1. Average Estonian 2014 electricity spot price during a day.

\section{IMPROVEMENT OF VALUE STREAM MAPPING METHODOLOGY FOR EVALUATION OF LOAD SCHEDULING POSSIBILITIES}

\section{A. Load Scheduling at Intermediate Storage Use in Production}

In the following, LS possibilities are examined for intermediate storage use as an energy saving unit, to enable shifting of energy intense production from HPP to LPP. In LS, it is important to understand energy intensive production units and their overall role in the production. Methods from lean philosophy [LP] can be used here. We propose to improve the value stream mapping (VSM) methodology with LS principles. Today LP is a leading production management philosophy. VSM is used to plan production as efficiently as reasonably possible. Energy intensity can be added in a process as additional information for a VSM, which will give a good overview about the possibilities in energy saving. Fig. 2 gives an overall picture of a typical VSM, elaborated with process energy intensity and amount of energy stored in the production intermediate storage. 


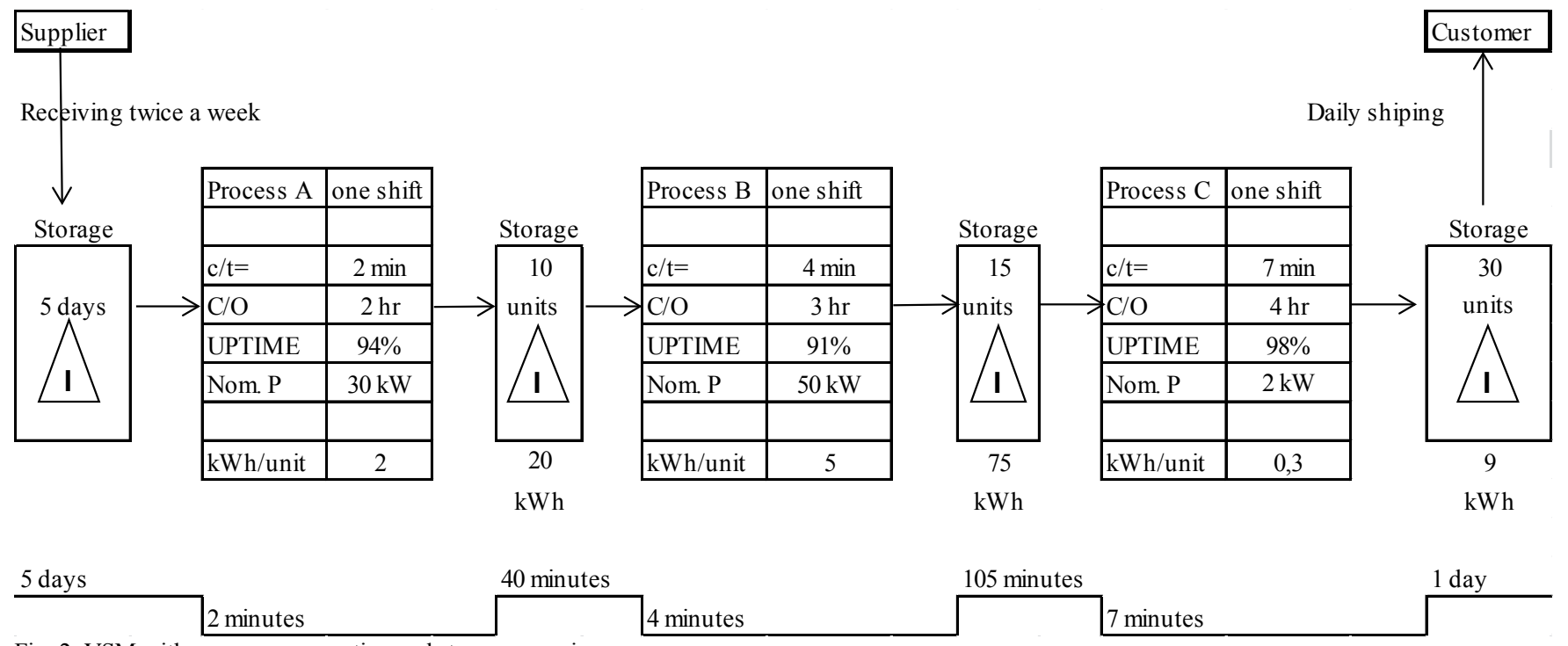

Fig. 2. VSM with energy consumption and storage overview.

As VSM gives an overview of the production planning and can additionally give information about energy intensity, the possibility of the LS should be studied in detail. From VSM, we will know if an energy intense process is at the same time a bottleneck in production. If it is not true, then the conclusion is that this process is not $100 \%$ utilized in time and LS can be implemented without increasing process capacity. Alternatively costs for increasing process capacity (CPC) need to be calculated.

Next, we focus on the storage. If production is shifted in time, storage volume can increase as compared to the state without LS utilized. Storage increase may need additional investments, which should also be considered as costs for storage (CS). Also, costs of the process (CP) itself for LS should be taken into account. As an example CP related to LS can be an increase in labor costs due to night shifts. Finally, if the costs related to LS are lower than a possible income from LS (ILS), the LS can be implemented in the industrial process. This criterion is given in the following (2):

$$
\mathrm{CPC}+\mathrm{CS}+\mathrm{CP}<\mathrm{ILS} .
$$

\section{B. Methodology for LS with VSM.}

The main initial goal of LP and VSM was to reduce lead time $(\mathrm{L} / \mathrm{T})$, i.e, the time it takes to move a produced piece all the way in the process or production from start until to the end. As a result, many costs or wastes, as defined in LP, will be reduced. As shown in (2), income from LS should be higher than costs related to it because LS can increase the intermediate stock and due to that it has a negative effect on the $\mathrm{L} / \mathrm{T}$ as well. VSM is a tool that will help to find the processes which have a reasonable effect and income. To achieve that, cost saving potential must be estimated. In section II, we showed a possible gain from LS in Estonia. The next step is to define the energy consumption of the processes. It is useful to combine that with VSM. If a company already has VSM, then energy consumption should be added into the VSM. VSM will highlight important information to be considered for LS. Most importantly, the following information must be taken into account:

a) Identify if the process is a bottleneck in production. If the process is a bottleneck, then load shifting is usually impossible without investment into the process output increase.

b) Process cycle time $(C / T)$ is slower or faster than its next process $C / T$. C/T in VSM describes how often a part or a product is completed by a process. If the process $C / T$ is slower than the process coming next, it is possible to increase intermediate stock at the end of the process coming after rather than at the end of the first process. In case the first process is faster than the next one, the LS applied will increase the intermediate stock.

c) Weather process uptime (UPTIME) is high or low, shows important information about process reliability. A low reliability process has a negative effect on $L S$.

d) If stock between processes is high or low, the reasons should be found out before applying load scheduling.

e) Change over time $(\mathrm{C} / \mathrm{O})$ is long or short. $\mathrm{C} / \mathrm{O}$ is the time period for switching the process unit from one product to another. It can show also time for cold start of the process. $\mathrm{C} / \mathrm{O}$ can highlight important information about the process start up time.

The best way to start defining the energy consumption of a process is to make the consumer list. Consumer list should be based on processes described with VSM. The consumer list may be available in the facility electrical department. In that case, consumer list is usually based on the power cabinets and it has to be made process by process. If the consumer list is not available, it should be done from scratch. As the purpose is to find an initial energy intensive process, the consumer list can be composed without actual measurements. The consumer list should contain the following information: process name; device 
label; rated power; $\cos _{\varphi}$; nominal current; nominal voltage and consumption type that can be either continuous, intermittent or stand by.

Upon completion of the consumer list, traditional VSM should be elaborated and total nominal loads in the process added. As a result, elaborated VSM will show which processes have sufficiently high energy intensity to gain benefits from LS and on the other hand, to estimate the particular potential to the process scheduling. After completing the estimation in conjunction with experts from production, the VSM should be elaborated further. Based on the measurements, energy intensity or the production unit is to be found. As the energy usage was previously estimated, measurements can be done in the production process where energy usage is estimated to be high or VSM shows that LS can be implemented without investing to process capacities or intermediate stocks.

As VSM describes product flow, the energy intensity should also be given per product or production unit. The unit energy consumption in the production process should be calculated based on the actual measurement. Fig. 2 shows a theoretical example of VSM together with data from the consumer list and energy intensity in the process. Energy intensity is energy consumption in each process to make one unit. As can be seen, process A C/T takes 2 minutes, i.e., one unit is completed during 2 minutes in the process. The total nominal power of the process is $30 \mathrm{~kW}$ and $2 \mathrm{kWh}$ is consumed to make one unit. First intermediate stock capacity (after process A) is 10 pieces. It consists of $20 \mathrm{kWh}$ energy which is available for scheduling. Process B C/T is 4 minutes and the total nominal power in that process is $50 \mathrm{~kW}$. As the second intermediate stock (after process B) capacity is 15 pieces, it has $75 \mathrm{kWh}$ energy available for scheduling. Process $\mathrm{C}$ cycle time is 7 minutes, total nominal power is $2 \mathrm{~kW}$ and $0.3 \mathrm{kWh}$ is consumed for making one unit. We can see that process $\mathrm{A} \mathrm{C} / \mathrm{T}$ is 2 times faster than process $\mathrm{B}$ and process $\mathrm{C}$ cycle time is 3.5 times faster than process $\mathrm{A}$. As a result, we can conclude that the last process will dictate the whole process time and previous processes can be scheduled taking into account the possibilities of the last process. For that reason, we need to know how much time it takes to empty the intermediate stock before the slowest process, which we call buffer time (BT). In order to find $\mathrm{BT}$, process $\mathrm{C} / \mathrm{T}$ must be multiplied with an available intermediate stock capacity (ASC) (3) and (4).

$$
\begin{aligned}
& A S C=M S C-S S C . \\
& B T=C / T \cdot A S C .
\end{aligned}
$$

ASC is a difference between maximum stock capacity (MSC) and safety stock capacity (SSC). SSC is to be defined by production management.

BT shows the maximum load scheduling period in the process. Neglecting safety stock capacity, in our example BT is 105 minutes. The total energy we can shift during 105 minutes is $95 \mathrm{kWh}$, which is the sum of stored energy in two intermediate stocks with 75 and $20 \mathrm{kWh}$ accordingly.

\section{EXPERIMENTAL LOAD SCHEDULING ANALYSIS IN A DISTRICT HEATING PLANT WITH IMPROVED VSM METHODOLOGY}

An example of the method above is described here. This example covers a district heating plant in Paide, Estonia. The company has one $8 \mathrm{MW}$ woodchip boiler, several boilers fuelled with shale-oil and one CHP plant based on woodchips and with $8 \mathrm{MW}$ thermal, $2 \mathrm{MW}$ electrical output. Fig. 3 shows the process of the plant. Woodchip boiler stock (moving floor) is filled by a conveyor from the main storage (moving floor). The main storage is filled by the incoming tucks or a wheel loader. The company has 5-day storage available on site. Woodchip boiler stock can contain woodchips a day with boiler nominal load i.e. $180 \mathrm{~m}^{3}$. The conveyor between the main storage and the woodchip boiler stock has a maximum output of $50 \mathrm{~m}^{3} / \mathrm{h}$. The conveyor from the woodchip boiler stock to the boiler has a strict limitation for processing output from the woodchip boiler. As it has no stock or daily silo available between the boiler and the conveyor, the output is $7.5 \mathrm{~m}^{3} / \mathrm{h}$ with the nominal boiler load. We start the cost reduction estimation from LS by modeling the process using VSM as a basis. One cubic meter of woodchips is taken here as one unit in VSM.

According to the conveyor output parameters, the total output time is 6 days and 15.2 minutes and the value creating time is 17.2 minutes (time when one cubic meter of woodchips is actually processed). Also, the VSM shows that the conveyor from the main to the boiler stock has excessive capacity and is able to process one cubic meter of woodchips approximately 6.67 times faster than the process bottleneck, i.e. woodchip boiler.

The boiler will process one cubic meter of woodchips into heat in 8 minutes. It can be concluded from VSM that there is a possibility of LS of the conveyor from the main storage to the boiler stock. It must be emphasized that we are dealing with a biomass conveyor; therefore, the following simplifications are used:

a) woodchip processing by a boiler is calculated based on the nominal load, and boiler efficiency parameter is 0.8 ;

b) woodchip energy intensity is approximated at 1.3 $\mathrm{MW} / \mathrm{m}^{3}$, in real life it can be different, based on the fuel type and humidity level.

The next task is to estimate process energy intensity by making a consumer list behind the process. In our example, it is evident from VSM that the only process that can be scheduled is the process called "Conveyor from Main Stock to Boiler Stock". Thus, we need to make a consumer list behind this process, which is given in Table I

Table I shows that the total nominal power behind the process is $73.5 \mathrm{~kW}$. The consumer list is necessary to estimate of the process energy demand. It is possible that some consumer's nominal power is much greater than the actual absorbed power. Therefore it is necessary to measure the process energy use. 
TABLE I

CONSUMER LIST FOR CONVEYOR FROM MAIN STOCK TO BOILER STOCK

\begin{tabular}{|c|c|c|c|c|c|}
\hline Description & Pn & $\overline{C o s} \phi$ & In & Un & Consumption \\
\hline $\begin{array}{l}\text { Conv. Screen to } \\
\text { dist. Conv. }\end{array}$ & 15 & 0.8 & 46.9 & 0.4 & Continuous \\
\hline Distr. conveyor & 7.5 & 0.8 & 23.4 & 0.4 & Continuous \\
\hline $\begin{array}{l}\text { Floor to } \\
\text { conveyor motor }\end{array}$ & 4 & 0.8 & 8.6 & 0.4 & Continuous \\
\hline $\begin{array}{l}\text { Floor to } \\
\text { conveyor motor }\end{array}$ & 4 & 0.8 & 8.6 & 0.4 & Continuous \\
\hline Hydro pack & 15 & 0.85 & 28.9 & 0.4 & Intermittent \\
\hline Hydro pack & 15 & 0.85 & 28.9 & 0.4 & Intermittent \\
\hline Screen & 5.5 & 0.81 & 11.4 & 0.4 & Continuous \\
\hline $\begin{array}{l}\text { Conv. floor to } \\
\text { screen }\end{array}$ & 7.5 & 0.8 & 23.4 & 0.4 & Continuous \\
\hline
\end{tabular}

In our example, Fluke 1735 is used for measurements of the process energy use and current measurements for some continuous consumption. There is calculated absorbed power with the following (5).

$$
P=3 \cdot I_{f} \cdot U_{f} \cdot \cos _{\varphi},
$$

where $\mathrm{P}$ is absorbed power, If- phase current, Uf- phase voltage and $\cos _{\varphi}$ is power factor. By using absorbed power for a continuous load, energy consumption was estimated as well. Total energy consumption for processing $1 \mathrm{~m}^{3}$ of woodchips was $0.96 \mathrm{kWh}$. Complete VSM for the process examined is

given in Fig. 3.

The VSM shows that by processing one cubic meter of woodchips there is consumed $0.96 \mathrm{kWh}$ of electrical energy. As there is storage available with $180 \mathrm{~m} 3$ and SSC is $7.5 \mathrm{~m} 3$, ASC is $172.5 \mathrm{~m} 3$ using (3). By knowing process $\mathrm{C} / \mathrm{T}$ behind the intermediate stock- it is 8 minutes per $\mathrm{m} 3$. There can be found out that BT is 23 hours by using (4).

We can conclude that BT is sufficiently long for considering LS from HPP to LPP given in section II. Paide boiler plant is connected to a grid at low voltage line, so the grid tariffs applicable will be different from those given in section II. HPPP for the current example is 83.4 euros per MWh with 43.5 euros per MWh grid tariff and LPPP is 55.2 euros per MWh with 25.7 euros per MWh grid tariff. Based on (1), we can calculate potential saving which is $33.8 \%$.

As stored energy in the process is $0.166 \mathrm{MWh}$, by multiplying that with HPPP, the cost for the company will be 13.81 euros per day and saving from LS will be 4.67 euros per day.

In the previous example, the VSM process is not complicated; however, VSM is essential in case production is more complicated and processes are more complex and dependent on each other. In that case, VSM enables cost savings with LS. Moreover, LS is well understandable with VSM for staff involved in production management and planning.

\begin{tabular}{|c|c|c|c|c|c|c|c|c|c|}
\hline Supplier & & & & & & \multirow{2}{*}{\multicolumn{2}{|c|}{ Paide Boiler Plant }} & & Customer \\
\hline \multicolumn{4}{|c|}{ reçiving daily } & & & & & \multicolumn{2}{|c|}{ continuous heat \$upply } \\
\hline Storage & & \multicolumn{2}{|c|}{$\begin{array}{c}\text { Conveyer from } \\
\text { Storage to Boiler } \\
\text { Stock }\end{array}$} & & & \multicolumn{2}{|c|}{$\begin{array}{c}\text { Conveyer from Boiler } \\
\text { Stock to Boiler }\end{array}$} & \multicolumn{2}{|c|}{ Boiler } \\
\hline \multirow{3}{*}{5 days } & & $\mathrm{c} / \mathrm{t}(\mathrm{min})$ & 1.2 & \multirow[b]{2}{*}{1 day } & \multirow[b]{2}{*}{$\rightarrow$} & $\mathrm{c} / \mathrm{t}(\mathrm{min})$ & 8 & $\mathrm{c} / \mathrm{t}(\mathrm{min})$ & 8 \\
\hline & & $\mathrm{C} / \mathrm{O}$ & 0 & & & $\mathrm{C} / \mathrm{O}$ & 0 & $\mathrm{C} / \mathrm{O}$ & $4 \mathrm{hr}$ \\
\hline & \multirow{3}{*}{$\left(\mathrm{m}^{3}\right)$} & Uptime & $95 \%$ & & \multirow{3}{*}{$\begin{array}{l}\left(\mathrm{m}^{3}\right) \\
(\mathrm{kWh})\end{array}$} & Uptime & $95 \%$ & Uptime & $95 \%$ \\
\hline \multirow[t]{2}{*}{600} & & Nom. P & $73.5(\mathrm{~kW})$ & 180 & & & & & \\
\hline & & $\mathrm{kWh} / \mathrm{m}^{3}$ & 0.96 & 173 & & & & $\mathrm{kWh} / \mathrm{m}^{3}$ & 0.3 \\
\hline \multirow[t]{2}{*}{5 days } & & & & 1 day & & & & & \\
\hline & & \multicolumn{2}{|c|}{$1.2 \mathrm{~min}$} & & & \multicolumn{2}{|l|}{$8 \mathrm{~min}$} & \multicolumn{2}{|c|}{$8 \mathrm{~min}$} \\
\hline
\end{tabular}

Fig. 3 VSM for LS for Paide district heating company..

\section{CONCLUSION}

Various aspects of DSR were studied. Focus was on the price difference in the electricity stock market in Estonia. If the loads are shifted from HPP to LPP LS will enable a cost reduction of $31 \%$. The methodology based on VSM was introduced where cost savings were achieved with LS. Our analysis of experimental load scheduling was based on the district heating company in Estonia. The proposed methodology was found to be applicable as a straightforward tool to achieve cost savings. It can serve as first step for industry when implementing LS because of its simplicity. With minor costs, reduced time and lower complexity, a major cost saving can be achieved with simple solutions such as the method proposed. 


\section{REFERENCES}

[1] P. Kontogiorgos and G. P. Papavassilopoulos, "Subsidized power interruption for reducing peaks in energy demand: A stackelberg game," Communications, Control and Signal Processing (ISCCSP), 2014 6th International Symposium on, Athens, 2014, pp. 421-424. doi: 10.1109/ISCCSP.2014.6877903

[2] G. Carpinelli, S. Khormali, F. Mottola and D. Proto, "Demand response and energy storage systems: An industrial application for reducing electricity costs. Part II: Numerical application," Power Electronics, Electrical Drives, Automation and Motion (SPEEDAM), 2014 International Symposium on, Ischia, 2014, pp. 1038-1042. doi: 10.1109/SPEEDAM.2014.6872040

[3] S. A. Raziei and H. Mohscnian-Had, "Optimal demand response capacity of automatic lighting control," Innovative Smart Grid Technologies (ISGT), 2013 IEEE PES, Washington, DC, 2013, pp. 1-6. doi: 10.1109/ISGT.2013.6497854

[4] M. Houwing, R. R. Negenborn and B. De Schutter, "Demand Response With Micro-CHP Systems," in Proceedings of the IEEE, vol. 99, no. 1, pp. 200-213, Jan. 2011. doi: 10.1109/JPROC.2010.2053831

[5] A. Rosin, I. Drovtar, S. Link, H. Hõimoja, H. Mõlder and T. Möller, "Analysis of large electricity consumers demand profiles to determine implementation of demand-side management measures", "Tarbimise juhtimine - suurtarbijate koormusgraafikute salvestamine ning analüüs juhtimise rakendamise võimaluste tuvastamiseks," Eleringi toimetised, pp. 1-57, 20 October 2014.

[6] S. Mohagheghi and N. Raji, "Dynamic demand response solution for industrial customers," Industry Applications Society Annual Meeting, 2013 IEEE, Lake Buena Vista, FL, 2013, pp. 1-9. doi: $10.1109 /$ IAS.2013.6682583

[7] A. Mohamed and M. T. Khan, "A review of electrical energy management techniques:supply and consumer side (industries)," Journal of Energy in Southern Africa, vol. 20, no. 3, 2009.

[8] A. Kuhi Thalfeldt and P. Raesaar, "Possibilities and feasibility of demandside management in the Estonian industrial sector," in 5 th International Symposium "Topical Problems in the Field of Electrical and Power Engineering", Kuressaare, 2008.

[9] T. Ohno, "Toyota production system: beyond large-scale production", Portland, 1988.

[10] B. Haefnera, A. Kraemera, T. Staussa and G. Lanzaa, "Quality value stream mapping," in 47th CIRP Conference on Manufacturing Systemss, Windsor, 2014.

[11] P. Uuemaa, J. Valtin, J. Kilter, A. Puusepp, I. Drovtar and A. Rosin, "Load control implementation in the energy intensive industry," Mediterranean Electrotechnical Conference (MELECON), 2014 17th IEEE, Beirut, 2014, pp. 213-218. doi: 10.1109/MELCON.2014.6820534

[12] I. Drovtar, P. Uuemaa, A. Rosin, J. Kilter and J. Valtin, "Using demand side management in energy-intensive industries for providing balancing power - The Estonian case study," Power and Energy Society General Meeting (PES), 2013 IEEE, Vancouver, BC, 2013, pp. 1-5. doi: 10.1109/PESMG.2013.6672418

[13] P. Uuemaa, J. Kilter, J. Valtin, I. Drovtar, A. Rosin and A. Puusepp, "Cost-effective optimization of load shifting in the industry by using intermediate storages," Innovative Smart Grid Technologies Europe (ISGT EUROPE), 2013 4th IEEE/PES, Lyngby, 2013, pp. 1-5. doi: 10.1109/ISGTEurope.2013.6695404

[14] AS, Nord Pool Spot, "Elspot_prices_2014_hourly_EUR," 2014. [Online]. Available: http://www.nordpoolspot.com/historical-market-data. [Accessed 20 June 2015].

[15] Elektrilevi OÜ, "Price list fo Elektrilevi from 01.04.2014", "Elektrilevi hinnakiri alates 01.04.2014," 1th April 2014. [Online]. Available: www.elektrlilevi.ee/hinnakiri. [Accessed 19th June 2015] 